A Avaliação do Impacto do Novo Texto Constitucional nas Alíquotas de Contribuições 1 Sociais e Previdenciárias

\title{
AVALIAÇÃO DO IMPACTO DO NOVO TEXTO CONSTITUCIONAL NAS ALIQUOTAS DE CONTRIBUIÇÕES SOCIAL ES PREVIDENCIÁRIAS
}

\author{
Welington Rocha \\ Professor do Departamento de Contabilidade e Atuaria \\ da Faculdade de economia e administração \\ da universidade de São Paulo FEA/USP
}

\section{I - Introdução}

Os direitos sociais estabelecidos no artigo $7^{\circ}$ da Constituição de 1.988 , b em como as disposições relativas à Seguridade Social, deverão elevar as taxas de contribuições sociais atualmente pagas pelos empregadores.

O sistema previdenciário necessitará de recurso adicionais para custear os novos benefícios criados pela Carta Magna, Tais como:

\section{Licença e Proteção à Gestante}

(art. 7으, inciso XVIII e art. 201, inciso III):

Ampliada de 80 para 120 dias para as trabalhadoras urbanas. Transformada em direito previdenciário para as rurais. Estendida às empregadas domésticas.

\section{Licença-Paternidade de Cinco Dias}

(art. 10ํำ parágrafo 1ำ das Disposições Transitórias e art.7ํㅡㄹ inciso XIX).

\section{Seguro-Desemprego}

(art. $7^{\circ}$, inciso II, atr. 201, inciso IV e art. 239, parágrafo $4^{\circ}$ )

4. Equivalência de benefícios às populações urbanas e rurais. (Art. 194, inciso 2)

5. Ajuda à manutenção dos dependentes dos segurados de baixa renda (art. 201, inciso II)

6. Pensão ao marido ou companheiro pela morte da segurada (art. 201, inciso V)

7. Pisos de benefícios equivalentes ao salário mínimo (art. 201, parágrafo 5º)

8. $13^{\circ}$ salário aos aposentados e pensionistas com base no valor dos proventos do mês de Dezembro (art.201, parágrafo 6ํ)

9. Correção monetária sobre os 36 últimos salários de contribuição para fins de aposentadoria (art.202, caput)

10. Antecipação da idade limite para concessão de aposentadoria aos trabalhadores rurais (art. 202, inciso I ) 
11. Garantia de salário mínimo aos idosos e deficientes (art. 203, inciso V)

12. Revisão dos valores dos benefícios em manutenção convertendo-os em números de salários mínimos ( art. 58 das Disposições Transitórias).

Objetivo deste trabalho é tentar avaliar o impacto desses novos direitos nos gastos das empresas com a previdência, ou seja, tentar responder à pergunta: "em quanto aumentaram as contribuições previdenciárias em conseqüência da nova constituição?".

Deve ficar claro que não se trata de recalcular os encargos sociais todos em função da nova carta.

Par isto, seria necessário estudar, também os impactos causados pelo aumento do valor das Folhas de Salários, o que não é abordado neste trabalho:

\section{II - SITUAÇÃO ANTERIOR}

As principais contribuições sociais devidas pela maioria das empresas industriais vigentes até a Constituição de 1.988, podem ser agrupadas da seguinte maneira:

1- Contribuição incidente sobre a receita: PIS $(0,35)$

2- Contribuição incidente sobre o faturamento: FINSOCIAL $(0,5 \%)$

3- Contribuição incidente sobre Folha de Pagamento: $(33,15 \%)$

4- Contribuição incidente sobre o lucro: PIS-IR (5\% sobre 35\%)

\section{Resumindo temos:}

Sobre a Folha de Pagamento

$\begin{array}{ll}\text { FPAS SOBRE SALÁRIOS } & 10,00\end{array}$

$\begin{array}{ll}\text { FPAS SOBRE } 13^{\circ} \text { salário } & 0,75\end{array}$

$\begin{array}{ll}\text { Salário-família } & 4,00\end{array}$

Salário-maternidade $\quad 0,30$

Previdência Social Rural $\quad 2,40$

Sub-Total-1

17,45

$\begin{array}{ll}\text { Salário-Educação } & 2,50\end{array}$

$\begin{array}{ll}\text { INCRA } & 0,20\end{array}$

$\begin{array}{ll}\text { SENAI } & 1,00\end{array}$

$\begin{array}{ll}\text { SESI } & 1,50\end{array}$ 
Sociais e Previdenciárias

\begin{tabular}{lc}
\hline Sub-total 2 & 5,20 \\
\hline Seguro Contra Acidentes & 2,50 \\
Fundo de Garantia & 8,00 \\
\hline Sub-total - 3 & 10,50 \\
\hline TOTAL & 33,15 \\
\hline & \\
2- Sobre a Receita (PIS) & 0,35 \\
3- Sobre o Faturamento (FINSOCIAL) & 0,50 \\
4- Sobre o lucro (PIS-IR) & 1,75
\end{tabular}

\section{III- NOVA SITUAÇÃO}

O antiprojeto da lei de seguridade social encaminhado pelo governo ao Congresso Nacional estabelece novo plano de custeio e de benefícios previdenciários.

A medida provisória ํㅜ 63, de 1ํ de Junho de 1.989, antecipa alterações na Legislação de Custeio da Previdência Social.

O artigo $5^{\circ}$ da MP-63 estabelece as seguintes alíquotas de contribuições incidentes sobre a folha de pagamento.

1- $20 \%$ (Vinte por Cento) "para custear os benefícios em geral, substituindo os $17,45 \%$ demonstrados no sub-total 1 do quadro anterior.

2- 2\% (Dois por cento) "Para financiamento da complementação das prestações por acidente do trabalho" abandonando -se as três alíquotas anteriormente vigentes, segundo o grau de risco da atividade.

Assim sendo, as empresas industriais em geral passarão a contribuir de acordo com as seguintes taxas incidentes sobre a folha:

$\begin{array}{lr}\text { Taxa única para Previdência Social } & 20,00 \% \\ \text { Contribuições para terceiros (sub-total } 2 \text { do quadro anterior) } & 5,20 \% \\ \text { Seguro conta Acidentes do Trabalho (a) } & 2,00 \% \\ \text { Fundo de Garantia } & 8,00 \% \\ \text { Total } & 35,20 \%\end{array}$

Haverá uma contribuição adicional (de $0,5 \%$ a 1,8\%) para as empresas cujo índice de acidente seja superior à média do respectivo setor.

Por outro lado o artigo 9 da mesma MP-63 eleva a alíquota de Contribuição ao FINSOCIAL, incidente sobre o faturamento das empresas, de $0,5 \%$ (meio por cento) para $1 \%$ (um por cento).

Anteriormente a Lei no 7.689 de 14/12/88 criou a Contribuição Social de 8\% (oito por cento) incidente sobre o lucro o lucro liquido antes do Imposto de Renda, dedutível para efeito de apuração de o próprio IR. 
A Avaliação do Impacto do Novo Texto Constitucional nas Alíquotas de Contribuições 4 Sociais e Previdenciárias

\section{Resumindo, temos:}

1- Sobre a Folha de Pagamento em \% Antes Depois

FPAS SOBRE SALÁRIOS

$10,00 \quad$ N.D

FPAS Sobre $13^{\circ}$ Salário

$0,75 \quad$ N.D

Salário-família

$4,00 \quad$ N.D

Salário-Maternidade

$0,30 \quad$ N.D

Previdência Social Rural

$0,40 \quad$ N.D

Sub-total 1

$17,45 \quad 20,00$

\begin{tabular}{lcc}
\hline Salário-Educação & 2,50 & 2,50 \\
INCRA & 0,20 & 0,20 \\
SENAI & 1,00 & 1,00 \\
SESI & 1,50 & 1,50 \\
\hline Sub-total 2 & 5,20 & 5,20 \\
\hline Seguro Contra Acidentes & 2,50 & 2,00 \\
Fundo de Garantia & 8,00 & 8,00 \\
& & 10,00 \\
\hline Sub-total 3 & 10,50 & 35,20 \\
\hline TOTAL & 33,15 & \\
\hline N.D = Não discriminado & & 0,35 \\
& & 1,00 \\
2. Sobre a Receita (PIS) & 0,35 & 0,00 \\
3. Sobre o Faturamento (FINSOCIAL) & 0,50 & 7,41 \\
4. Sobre o Lucro (PIS-IR) & 0,00 &
\end{tabular}

\section{V - AVALIAÇÃO DO IMPACTO}

Consideramos uma empresa industrial imaginária com os seguintes dados de atividade:

Receita Total:

Faturamento:

Margem de Lucro sobre a receita:

$$
\begin{gathered}
\$ 12.000,00 \\
\$ 10.000,00 \\
10 \%
\end{gathered}
$$


A Avaliação do Impacto do Novo Texto Constitucional nas Alíquotas de Contribuições 5 Sociais e Previdenciárias

Valor da Folha de Salário

Grau de Risco de Acidentes:
$\$ 1.000,00$

Grave

1. CONTRIBUIÇÃO SOBRE A RECEITA (pis)

Antes: $\quad 0,0035 \times \$ 12.000,00=\$ 42,00$

Depois: $0,0035 \times \$ 12.000,00=\$ 42,00$

\section{CONTRIBUIÇÃO SOBRE O FATURAMENTO}

Antes: $\quad 0,005 \times 10.000,00=\$ 50,00$

Depois: $0,010 \times 10.000,00=\$ 100,00$

3. CONTRIBUIÇÃO SOBRE A FOLHA DE PAGAMENTO

Antes: $0,3315 \times \$ 1.000,00=\$ 331,50$

Depois: $0,3520 \times \$ 1.000,00=\$ 352,00$

4. CONTRIBUIÇÃO SOBRE O LUCRO (Para a Previdência)

Antes: Inexistente

(O lucro antes do Imposto de Renda seria de $0,1 \times \$ 12.000,00=\$ 1.200,00$ )

\section{Depois:}

Lucro Anterior

(-) Contr.Adicional sobre o faturamento

(-) Contr.Adicional sobre salários

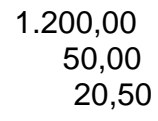

\section{LUCRO ANTES DA CONTRIB.SOCIAL E DP IR $1.129,50$}

Como a base de cálculo (BC) da Contribuição Social (CS) é Lucro (L) Já deduzido da própria CS, temos:

$$
\begin{aligned}
B C & =L-C S \\
\text { e } C S & =0,08 \times B C
\end{aligned}
$$

Logo: $\quad C S=0,08(L-C S)$

$$
\begin{aligned}
C S=0,08 \mathrm{~L}-0,08 \mathrm{CS} \\
\mathrm{CS}+0,08 \mathrm{CS}=0,08 \mathrm{~L} \\
1,08 \mathrm{CS}=0,08 \mathrm{~L} \\
\mathrm{CS}=0,08 \mathrm{~L} / 1,08 \\
\mathrm{CS}=0,07407407 \text { L ou seja: }
\end{aligned}
$$

$7,407407 \%$ do LUCRO 
A Avaliação do Impacto do Novo Texto Constitucional nas Alíquotas de Contribuições 6 Sociais e Previdenciárias

Portanto a Contribuição Social será de

$7,407407 \%$ sobre $\$ 1.129,50=$

$=\$ 83,64$

\section{CONTRIBUIÇÃO SOBRE O LUCRO (PIS-IR)}

Antes: $0,05 \times 0,35 \times \$ 1.200,00=$

$=0,0175 \times \$ 1.200,00=\$ 21,00$

Depois: Inexistente

(O lucro antes do Imposto de Renda seria de $\$ 1.129,50-\$ 83,64=1.045,86$ )

\section{IMPOSTO DE RENDA}

Antes: $0,35 \times 1.200,00-21,00=$

$$
420,00-21,00=\$ 399,00
$$

Depois: $0,30 \times 1.045,86=313,76$

\section{V- CONCLUSÃO}

O impacto causado pela nova carta Magna nos gastos com contribuições sociais da maioria das empresas industriais pode ser resumido da seguinte maneira:

- $\quad$ PIS sobre a receita: Inalterado em 0,35

FINSOCIAL sobre o faturamento: Majorado em $100 \%$ ao passar de $0,5 \%$ para $1 \%$

Contribuições sobre salários: majoradas em $6,184 \%$ ao passar de 33,15\% PARA 35,20\%

Contribuição Social sobre o lucro (nova): 7,41\%

PIS sobre o imposto de renda, extinto

Imposto de Renda: caiu de $35 \%$ para $30 \%$.

Os efeitos dessas inovações sobre a receita e sobre o lucro das empresas variam de caso a caso dependendo, principalmente, da parcela salarial - contida no valor adicionado.

Entretanto podemos estimar esses impactos se admitirmos as hipóteses e as proporções consideradas no exemplo. Nessas condições teríamos:

\begin{tabular}{lrrrr}
\hline SITUAÇÃO & ANTES & $\%$ & DEPOIS & $\%$ \\
\hline Faturamento & $10.000,00$ & 83,00 & $10.000,00$ & 83,00 \\
Outras Receitas & $2.000,00$ & 17,00 & $2.000,00$ & 17,00 \\
\hline RECEITA TOTAL & $12.000,00$ & 100,00 & $12.000,00$ & 100,00 \\
\hline
\end{tabular}


A Avaliação do Impacto do Novo Texto Constitucional nas Alíquotas de Contribuições 7 Sociais e Previdenciárias

\begin{tabular}{|c|c|c|c|c|}
\hline FINSOCIAL & 50,00 & 0,42 & 100,00 & 0,83 \\
\hline PIS s/ RECEITA & 42,00 & 0,35 & 42,00 & 0,35 \\
\hline RECEITA LIQUIDA $\left(^{*}\right)$ & $11.908,00$ & 99,23 & $11.858,00$ & 98,82 \\
\hline DESPESAS & $10.708,00$ & 89,23 & $10.728,50$ & 89,40 \\
\hline Salários & $1.000,00$ & & $1.000,00$ & \\
\hline Contrib. S/ Salários & 331,50 & & 352,00 & \\
\hline Outras & $9.376,50$ & & $9.376,50$ & \\
\hline LUCRO PARCIAL & $1.200,00$ & 10,00 & $1.129,50$ & 9,42 \\
\hline Contrib.Social & & & 83,64 & 0,70 \\
\hline LUCRO ANTES DO IR & $1.200,00$ & 10,00 & $1.045,86$ & 8,72 \\
\hline Imp.de Renda & 420,00 & 3,50 & 313,76 & 2,61 \\
\hline LUCRO DEPOIS DO IR & 780,00 & 6,50 & 732,10 & 6,11 \\
\hline
\end{tabular}

(*) Desconsideradas outras deduções da Receita

Verifica-se que o lucro liquido depois do IR decresceu em $6,14 \%$.

\section{Ou seja:}

$(780,00-732,10) / 780,00=0,06141=6,14 \%$

Para que a empresa consiga retornar ao nível anterior de lucro $(\$ 780,00)$ terá que aumentar seus preços de venda de modo a gerar um faturamento que leve àquele lucro. Teríamos então:

$$
\begin{aligned}
& \mathrm{RT}=\mathrm{F}+\mathrm{R} \\
& \mathrm{RL}=\mathrm{RT}-(0,01 \mathrm{~F})-(0,0035 \mathrm{RT}) \\
& \mathrm{LP}=\mathrm{RL}-\mathrm{D} \\
& \mathrm{LAIR}=\mathrm{LP}(1-0,07407) \\
& \operatorname{LDIR}=\operatorname{LAIR}(1-0,3)
\end{aligned}
$$

\section{Onde:}

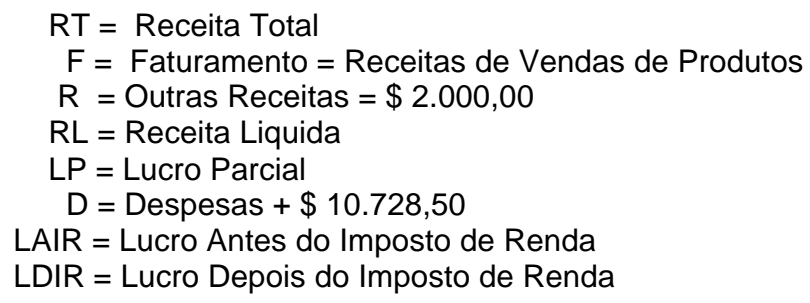




\section{Então:}

1. $\operatorname{LDIR}=\operatorname{LAIR}(1-0,3)$

$780,00=$ LAIR $\times 0,7$

$(780,00 / 0,7)=$ LAIR

LAIR $=\$ 1.114,2857$

2. $\operatorname{LAIR}=\operatorname{LP}(1-0,07407)$

$1.114,2857=\operatorname{LP} \times 0,92593(1.114,2857 / 0,92593)=L P$

$\mathrm{LP}=\$ 1.203,42$

3. $\mathrm{LP}=\mathrm{RL}-\mathrm{D}$

$1.203,42=R L-10.728,50$

$\mathrm{RL}=\$ 11.931,92$

4. $R L=R T-(0,01 F)-(0,0035 R T)$

$R L=R+F-(0,01 F)-(0,0035 R)-(0,0035 F)$

$11.931,92=2.000,00+F-0,01 F-7,00-0,0035 F$

$11.931,92=1.993,00=0,9865 \mathrm{~F}$

$9.938,92=0,9865 \mathrm{~F}$

$F=\$ 10.074,93$

Logo o faturamento terá que aumentar $(10.074,93 / 10.000,00)-1=0,007493=0,75 \%$

Para que a empresa retorne ao nível de lucro anterior de $\$ 780,00$

Para Comprovar, façamos a demonstração do resultado.

Faturamento

Outras Receitas

Receita Total

Finsocial

PIS s/ Receita

Receita Líquida

Despesas

Lucro Parcial

Contr. Social

Lucro A .I R

Imposto de Renda

Lucro Depois do IR
$10.074,93$

$2.000,00$

$12.074,93$

100,75

42,26

$11.931,92$

$10.728,50$

$1.023,42$

89,14

$1.114,28$

334,28

780,00

Portanto, para continuar auferindo o mesmo lucro com a nova situação a empresa deverá aumentar seus preços de venda em $0,75 \%$ 